\title{
Las medidas provisionales administrativas. Novedades incorporadas por el artículo 56 de la Ley 39/2015, de 1 de octubre, de Procedimiento Administrativo Común de las Administraciones Públicas
}

Belén Marina Jalvo

DOI: https://doi.org/10.47623/ivap-rvap.109.2017.1.05

\begin{abstract}
Sumario: I. Consideraciones generales. -II. Ámbito de aplicación de la regulación establecida por el artículo 56 de la Ley 39/2015, de 1 de octubre, de Procedimiento Administrativo Común de las Administraciones Públicas. - III. Finalidades que pueden ser atendidas con la adopción de medidas provisionales.-IV. Momento de adopción de las medidas provisionales: 1. En especial, el régimen de adopción de las medidas previas al inicio del procedimiento. $-\mathrm{V}$. La audiencia previa al interesado. - VI. Principios rectores de la adopción de medidas provisionales. - VII. La necesaria motivación del acuerdo de adopción de medidas provisionales. - VIII. Las medidas provisionales de posible adopción en los procedimientos administrativos: 1. La remisión a la Ley $1 / 2000$, de 7 de enero, de Enjuiciamiento Civil. 2. Medidas provisionales de posible adopción.-IX. Valoración final.
\end{abstract}

\section{Consideraciones generales}

La Ley 39/2015, de 1 de octubre, del Procedimiento Administrativo Común de las Administraciones Públicas (LPAC, en adelante), regula en su art. 56 las medidas provisionales, que podrán tener por objeto asegurar la eficacia de la resolución que pueda recaer en el procedimiento administrativo, la protección provisional de los intereses implicados o, tal como también ahora menciona expresamente la LPAC, la protección de los derechos de los interesados o la efectividad de la resolución final. Todo ello, si existiesen elementos de juicio suficiente, es decir, si la efectividad de la resolución final o de los intereses o derechos mencionados resultase amenazada durante la tramitación del procedimiento.

Las medidas provisionales podrán acordarse antes de la iniciación del procedimiento administrativo o iniciado dicho procedimiento [apartados 2) y 1) del art. 56 LPAC, respectivamente], según preveía ya el art. 72 de la 
Ley 30/1992, de 26 de noviembre, de Régimen Jurídico de las Administraciones Públicas y del Procedimiento Administrativo Común (LRJPAC, en lo sucesivo) (1).

Tal como ya señalaba la LRJPAC(2), no podrán adoptarse medidas provisionales que puedan causar perjuicios de imposible o difícil reparación a los interesados o que impliquen violación de derechos amparados por las leyes (3).

También en línea de continuidad con la LRJPAC (art. 72.4), dispone la LPAC (art. 56.5) que las medidas provisionales podrán ser alzadas o modificadas durante la tramitación del procedimiento, de oficio o a instancia de parte, en virtud de circunstancias sobrevenidas o que no pudieron ser tenidas en cuenta en el momento de su adopción. No resulta muy adecuada esta dicción de la ley que configura de forma facultativa el levantamiento o la modificación de las medidas adoptadas en caso de variación de las circunstancias en las que se hubiera fundado su adopción. Por el contrario, la extinción o modificación de las medidas provisionales acordadas será preceptiva si así deriva de la apreciación de las circunstancias no consideradas inicialmente (4).

En todo caso, si las medidas adoptadas no se hubiesen alzado con anterioridad, éstas se extinguirán «(...) cuando surta efectos la resolución administrativa que ponga fin al procedimiento"(5). Puesto que la extinción de las medidas provisionales queda condicionada a la eficacia de la resolución final (6), tratándose de resoluciones sancionadoras, la duración de las medidas adoptadas en el procedimiento administrativo puede prolongarse hasta la firmeza administrativa de las mismas (art. 90.3 LPAC) e, incluso, extenderse hasta el momento en que se produzca el correspondiente pronunciamiento judicial sobre la solicitud de medida cautelar en el proceso contencioso-administrativo (art. 117.4 LPAC).

(1) Sobre la regulación de las medidas provisionales que llevaba a cabo el art. 72 LRJPAC, con carácter general, pueden verse, entre otros trabajos, MARINA JALVO, Belén, Las medidas provisionales en la actividad administrativa, Lex Nova, Valladolid, 2007; REBOLLO PUIG, Manuel, "Medidas provisionales en el procedimiento administrativo", en La protección jurídica del ciudadano. Estudios en Homenaje al Profesor Jesús González Pérez, Tomo I, Civitas, Madrid, 1993.

(2) Art. 72.3.

(3) Ahora, art. 56.4 LPAC.

(4) En este sentido, vid., también, GONZÁLEZ RíOS, Isabel, «Reglas generales de ordenación e instrucción del procedimiento", en GAMERO CASADO, Eduardo (Dir.), Tratado de Procedimiento Administrativo Común y del Régimen Jurídico Básico del Sector Público, Tirant lo Blanch, Valencia, 2017, pág. 1543.

(5) Art. 72.4 LRJPAC y art. 56.4 LPAC.

(6) Pese al carácter instrumental de las medidas provisionales, vinculadas en última instancia a la eficacia de la resolución que ponga fin al procedimiento, y sin perjuicio de que puedan ser alzadas en un momento anterior, hay quien considera que la LPAC debería haber concretado el plazo máximo de duración de éstas. Vid., GALLARDO CASTILLO, María Jesús, Los procedimientos administrativos en la Ley 39/2015, Tecnos, Madrid, 2016, pág. 203. 
Ahora bien, según deriva de lo ya expuesto, el art. 56 no es el único precepto de la LPAC relativo a las medidas provisionales. Así, el art. 90.3 LPAC contempla la posibilidad de adoptar en la resolución que ponga fin a un procedimiento sancionador las disposiciones cautelares precisas para garantizar su eficacia en tanto no sea ejecutiva. Por otra parte, en los procedimientos administrativos de recurso podrán adoptarse, además de la medida cautelar de suspensión de la eficacia de los actos recurridos, que se regirá por las normas del art. 117 LPAC, las medidas necesarias para asegurar la protección del interés público o de terceros y la eficacia de la resolución o el acto impugnado (art. 117.4 LPAC). En rigor, como ya se habrá apreciado, la LPAC denomina "cautelares" a las medidas referidas en los mencionados artículos 90.3 y 117.4, por ser adoptadas cuando ya se ha dictado la resolución que pone fin al procedimiento, si bien ésta no es ejecutiva o su ejecución permanece suspendida. En realidad, estas medidas participan de la misma naturaleza de las medidas contempladas por el art. 56, puesto que, en ambos casos, concurre la nota de provisionalidad, y unas y otras tienen la finalidad cautelar de asegurar los fines pretendidos con la resolución.

Sin embargo, a diferencia de la LRJPAC, Ia LPAC no dedica ningún precepto a regular de forma singular las medidas provisionales que puedan acordarse en los procedimientos sancionadores, puesto que éstos no tienen ya la consideración de procedimientos especiales (7). Por ello, la LPAC ha derogado el Real Decreto 1398/1993, por el que se aprueba el Reglamento de Procedimiento para el Ejercicio de la Potestad Sancionadora (REPEPOS), que también contemplaba disposiciones especiales sobre las medidas provisionales (8). En consecuencia, las disposiciones del art. 56 LPAC pueden aplicarse sin más a la adopción de medidas provisionales en los procedimientos administrativos sancionadores, de manera que podrán ser acordadas las medidas precisas sin necesidad de que dicha posibilidad esté prevista en la normativa reguladora del procedimiento en cuestión.

Puesto que el objeto de este trabajo no consiste en un estudio pormenorizado del régimen de las medidas provisionales administrativas, sino en el análisis de la reforma realizada por la Ley 39/2015, a simple vista, si se compara el art. 56 LPAC con el art. 72 de la LRJPAC, se advierte que, sin perjuicio de una serie de elementos del régimen jurídico de estas me-

(7) No puede obviarse que, al regular los procedimientos sancionadores como simples reglas especiales del procedimiento administrativo común, la LPAC «(...) oscurece y rebaja su significado jurídico", Vid., SÁNCHEZ MORÓN, Miguel, "Una reforma precipitada, o la desarticulación gratuita del régimen jurídico de las Administraciones Públicas", El Cronista del Estado Social y Democrático de Derecho, 56, 2015, pág. 21.

(8) Para un análisis detallado de la regulación precedente de las medidas provisionales en el procedimiento sancionador, véase PONS CÁNOVAS, Ferrán, Las medidas provisionales en el procedimiento administrativo sancionador, Marcial Pons, Madrid, 2001. 
didas que han permanecido inalterados, la nueva normativa ha incorporado algunos aspectos novedosos en su regulación. Si bien las novedades referidas serán analizadas con el debido detalle en los apartados correspondientes de este trabajo, entre las más relevantes, destaca la exigencia de que las medidas previas a la iniciación del procedimiento resulten "necesarias y proporcionadas" (art. 56.2 LPAC). Respecto de estas medidas, es preciso destacar también que, a diferencia de lo dispuesto por el art. 72 LRJPAC, su adopción no queda limitada a los supuestos en que una norma con rango de ley así lo prevea expresamente sino que será posible en todo caso, pues tal exigencia ha desaparecido del texto del art. 56 LPAC.

En cuanto a las medidas adoptadas ya iniciado el procedimiento, dispone el art. 56 LPAC que deberán ser acordes con los principios de "proporcionalidad, efectividad y menor onerosidad".

También ahora el art. 56 exige que el acuerdo de medidas provisionales sea motivado, tanto cuando se adopte antes como después del inicio del procedimiento.

Por otra parte, en cuanto a las medidas provisionales de posible adopción (antes o después de iniciarse el procedimiento), el art. 56.3 LPAC se remite a la Ley $1 / 2000$, de 7 de enero, de Enjuiciamiento Civil (LEC, a partir de ahora), en el intento de establecer un listado de las mismas.

Sin ánimo de enumerar en este apartado todos los cambios introducidos por el art. 56 LPAC ni de adelantar una valoración detallada de la regulación que lleva a cabo este precepto, a la vista de las cuestiones señaladas en los párrafos anteriores, no parece precipitado afirmar que la norma mencionada ha optado por ampliar las facultades de las Administraciones Públicas relativas a la adopción de medidas provisionales, pero, por otra parte, también el acuerdo de estas medidas aparece sujeto a principios y exigencias que la LRJPAC no contemplaba expresamente.

\section{II. Ámbito de aplicación de la regulación establecida por el artículo 56 de la Ley 39/2015, de 1 de octubre, de Procedimiento Administrativo Común de las Administraciones Públicas}

Las disposiciones del art. 56 LPAC, como el resto de las normas relativas al procedimiento administrativo común a todas las Administraciones Públicas, se aplican al sector público en su conjunto, en los términos dispuestos por el art. 2 LPAC.

La nueva concepción del procedimiento administrativo común que, tal como señala el art. 1.1 LPAC, comprende el procedimiento sancionador y el procedimiento de reclamación de responsabilidad patrimonial de las Administraciones Públicas, comporta consecuencias nada desdeñables 
para la aplicación de la regulación de las medidas provisionales. Por lo que respecta singularmente al procedimiento sancionador, su consideración como procedimiento administrativo común, sin perjuicio de algunas especialidades en su tramitación(9), supone que las medidas provisionales que hayan de acordarse en su seno se regirán por las normas generales del art. 56 LPAC. No existen ya en la LPAC las normas especiales para la adopción de medidas provisionales en los procedimientos sancionadores que sí recogía la LRJPAC (art. 136)(10) y completaba el art. 15 del derogado REPEPOS(11). Por tanto, la posibilidad de adoptar medidas provisionales en los procedimientos sancionadores no queda ya reducida a los supuestos en que así esté previsto en sus normas reguladoras, ni limitada a las medidas concretamente previstas en las correspondientes normas específicas (art. 15.2 REPEPOS) (12), sino que, con carácter general, cabrá adoptar cualquier medida que se estime necesaria para asegurar la efectividad de la resolución [art. 56.3.i) LPAC] (13).

(9) Sobre las especialidades en la tramitación de los procedimientos sancionadores, véanse los arts. $62,63,64,85,89$ y 90 LPAC.

(10) Según disponía este precepto: «Cuando así esté previsto en las normas que regulen los procedimientos sancionadores, se podrá proceder mediante acuerdo motivado a la adopción de medidas de carácter provisional que aseguren la eficacia de la resolución final que pudiera recaer».

(11) En virtud del precepto citado: «1. De conformidad con lo previsto en los artículos 72 y 136 de la Ley de Régimen Jurídico de las Administraciones Públicas y del Procedimiento Administrativo Común, el órgano competente para resolver podrá adoptar en cualquier momento, mediante acuerdo motivado, las medidas de carácter provisional que resulten necesarias para asegurar la eficacia de la resolución que pudiera recaer, el buen fin del procedimiento, evitar el mantenimiento de los efectos de la infracción y las exigencias de los intereses generales.

Cuando así venga exigido por razones de urgencia inaplazable, el órgano competente para iniciar el procedimiento o el órgano instructor podrán adoptar las medidas provisionales que resulten necesarias.

2. Las medidas de carácter provisional podrán consistir en la suspensión temporal de actividades y la prestación de fianzas, así como en la retirada de productos o suspensión temporal de servicios por razones de sanidad, higiene o seguridad, y en las demás previstas en las correspondientes normas específicas.

3. Las medidas provisionales deberán estar expresamente previstas y ajustarse a la intensidad, proporcionalidad y necesidades de los objetivos que se pretenda garantizar en cada supuesto concreto".

(12) En relación con las especiales cautelas que los arts. 136 LRJPAC y 15 REPEPOS imponían en la adopción de medidas provisionales en los procedimientos sancionadores, y con la clara diferencia de la regulación que de las mismas llevaban a cabo los preceptos citados y el art. 72 LRJPAC, pueden verse, entre otras muchas, las SSTS de 15 de julio de 2008, recurso núm. 5357/2004, de 12 de marzo de 2012, recurso núm. 1070/2009, y 20 de marzo de 2012, recurso núm. 1501/2008, STSJ de la Comunidad Valenciana de 15 de octubre de 2010, recurso núm. 450/2008.

(13) En este sentido concluye también CANO CAMPOS, Tomás, lamentando que, a falta de disposiciones especiales sobre la adopción de medidas provisionales en los procedimientos sancionadores, "Ahora hemos de acudir a la regulación general de las medidas provisionales en el procedimiento administrativo común (art. 56), la cual ha sido criticada por atribuirle a la Administración una genérica y omnicomprensiva potestad que supone investir a la Administración de las mismas potestades que al juez», "El autismo del legislador: la "nueva» regulación de la potestad sancionadora de la Administración», RAP, núm. 201, 2016, pág. 54. 
Igualmente, el régimen de las medidas provisionales establecido en art. 56 LPAC será de aplicación en los procedimientos de recurso administrativo, cuando habiéndose acordado la suspensión del acto impugnado, éstas resulten necesarias para «(...) asegurar la protección del interés público o de terceros y la eficacia de la resolución o el acto impugnado» (art. 117.4 LPAC).

No obstante, el ámbito objetivo de aplicación directa del art. 56 LPAC se reduce en virtud de lo establecido en Disposición adicional primera de la misma norma. Así, con carácter general, la regulación de las medidas provisionales que lleva a cabo el art. 56 tendría, en su caso, mera aplicación supletoria en los procedimientos administrativos regulados en leyes especiales por razón de la materia (apartado 1 de DA 1. ${ }^{a}$ ), si éstos regulan de forma distinta el trámite de adopción de medidas provisionales. En todo caso, las normas reguladoras del procedimiento administrativo común $y$, en consecuencia, la regulación de las medidas provisionales, serían de aplicación supletoria en las actuaciones y procedimientos de aplicación de los tributos en materia tributaria y aduanera, así como su revisión en vía administrativa; en las actuaciones y procedimientos de gestión, inspección, liquidación, recaudación, impugnación y revisión en materia de Seguridad Social y Desempleo; y en las actuaciones y procedimientos en materia de extranjería y asilo [letras a), b) y d) del apartado 2 de la DA 1. ${ }^{\mathrm{a}}$.

En el caso de los procedimientos sancionadores, las disposiciones del art. 56 LPAC tendrían simple aplicación supletoria en las actuaciones y procedimientos en materia tributaria y aduanera, en el orden social, en materia de tráfico y seguridad vial y en materia de extranjería [letra c) del apartado 2 de la DA 1. ${ }^{\mathrm{a}}$.

\section{Finalidades que pueden ser atendidas con la adopción de medidas provisionales}

Se ha señalado ya que, de conformidad con el art. 56.1 LPAC, iniciado el procedimiento, y en los mismos términos dispuestos por el art. 72.1 LRJPAC, el órgano competente para resolver podrá adoptar las medidas provisionales que estime oportunas para asegurar la eficacia de la resolución que pudiera recaer. Según deriva del tenor literal de la norma, la finalidad perseguida con la adopción de la oportuna medida provisional sería la garantía de la ejecución de la resolución que ponga fin al procedimiento.

Cuando, tal como hacía el art. 72 LRJPAC, la LPAC prevé la posibilidad de que, antes de la iniciación del procedimiento administrativo, el órgano competente para iniciar o instruir dicho procedimiento pueda 
adoptar las medidas provisionales, de oficio o a instancia de parte, la finalidad propia de éstas consiste en la protección provisional de los intereses implicados (art. 56.2). En buena lógica, no se alude en este caso a la garantía de la eficacia o de la efectividad de la resolución que pudiera recaer, en un momento en que aún no se ha iniciado un procedimiento administrativo e incluso podría no incoarse posteriormente. Por tanto, en estos casos, la medida adoptada se orientará a la protección provisional de los intereses implicados, debiendo entender por tales los intereses confiados a la Administración en cada uno de los sectores de su actividad, así como los intereses y también los derechos invocados por quienes soliciten la adopción de la medida provisional y que, a su vez, les permitirían seguidamente - en condición de interesados(14) - instar la iniciación del procedimiento a la que se condiciona el mantenimiento de las medidas provisionales que se hubieran acordado con carácter previo.

Pese a que la LPAC refiera la protección provisional de los intereses implicados a las medidas provisionales de posible adopción antes de la iniciación del procedimiento, es obvio que esta misma finalidad puede ser atendida por las medidas provisionales acordadas al inicio o durante la tramitación del correspondiente procedimiento administrativo.

En refuerzo de lo dicho en los párrafos anteriores puede traerse a colación la referencia expresa que, por efecto de la remisión a la LEC, el art. 56.3.i) LPAC hace a la posibilidad de adoptar medidas que tengan por objeto la protección de los derechos de los interesados.

Reproduciendo también la dicción de la LEC (art. 727.11. ${ }^{a}$ ), el mismo art. 56.3.i) LPAC contempla de forma igualmente expresa la adopción de las medidas provisionales que se estimen necesarias para asegurar la efectividad de la resolución. De este modo, la LPAC pone de relieve otra finalidad que puede ser atendida por las medidas provisionales.

Importa resaltar que, como se ha dicho, además de las referencias a la garantía de la eficacia de la resolución que se dicte y a la protección de los intereses implicados que ya contemplaba el art. 72 LRJPAC, la LPAC ahora hace mención explícita de la protección de los derechos de los interesados y de la garantía de la efectividad de la resolución que se dicte, si bien no parece que estas nuevas referencias respondan a un propósito deliberado del legislador, y de ahí la dispersión de las mismas y la falta de la debida cohesión entre ellas. Dicho lo cual, no cabe ignorar que estas finalidades estaban ya presentes en la concepción de las medidas provisionales derivada de la regulación establecida en el art. 72 LRJPAC, así

(14) Vid., art. 4.1.a) LPAC. 
como en la práctica general de las medidas provisionales acordadas en los procedimientos administrativos (15).

Del conjunto de referencias del art. 56 LPAC a las diversas finalidades de las medidas provisionales (eficacia de la resolución, intereses implicados, derechos de los interesados y efectividad de la resolución), la relativa a la efectividad de la resolución es la más amplia y completa, pues comprende a todas las demás. Por tanto, el significado de la efectividad de la resolución va más allá de la mera garantía de la ejecución de la resolución que ponga fin al procedimiento, y debe ser interpretado en sentido amplio, entendiendo, como ha hecho la jurisprudencia, que «(...) las medidas cautelares van dirigidas a garantizar la efectividad del eventual resultado de un procedimiento administrativo o jurisdiccional, por lo que son procedentes cuando hay un serio peligro de que los intereses o derechos subjetivos que pudieran ser reconocidos o amparados en la futura resolución resultasen ya irrealizables o gravemente lesionados; y deben ser acordadas cuando todavía, por no haber finalizado el procedimiento, no se puede anticipar un juicio sobre el problema de fondo. Así resulta de una interpretación finalista del artículo 72 de la Ley 30/1992, de 26 de noviembre, de Régimen Jurídico de las Administraciones Públicas y del Procedimiento Administrativo Común, poniéndolo en relación con los preceptos que regulan la justicia cautelar en la Ley jurisdiccional»(16).

\section{Momento de adopción de las medidas provisionales}

Tal como ya contemplaba la LRJPAC, de conformidad con lo previsto por el art. 56 LPAC las medidas provisionales podrán adoptarse antes de la iniciación del procedimiento, en el mismo acto de iniciación o durante la tramitación del procedimiento.

En el caso de los procedimientos sancionadores, la ley contempla expresamente la posibilidad de adoptar medidas provisionales incluso en

(15) Es el caso, por ejemplo, de los procedimientos sancionadores, en los que la adopción de medidas provisionales es especialmente frecuente, y respecto de los cuales la doctrina de la Sala Tercera del Tribunal Supremo ha sostenido de forma reiterada que la actividad cautelar de la Administración pretende evitar "que el ilícito se produzca o que, producido, prolongue sus efectos o que el mismo se pueda reiterar». Vid., entre otras SSTS de 26 de mayo de 1989, 4 de febrero de

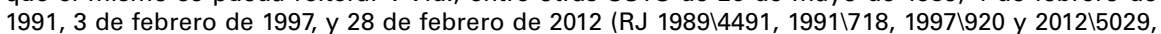
respectivamente).

El propio art. 15.1 del REPEPOS era bien explícito al señalar la posibilidad de adoptar en los procedimientos sancionadores las medidas provisionales necesarias para asegurar «(...) la eficacia de la resolución que pudiera recaer, el buen fin del procedimiento, evitar el mantenimiento de los efectos de la infracción y las exigencias de los intereses generales".

(16) STS de 1 de octubre de 2003, recurso núm. 914/1998. 
el momento mismo de dictar la resolución que ponga fin al procedimiento, y se mantendrán, en principio, hasta que dicha resolución sea firme en vía administrativa(17).

Por otra parte, tal como se ha adelantado en páginas anteriores, también en los procedimientos de recurso cabe adoptar las medidas provisionales que, para asegurar la protección del interés público o de terceros y la eficacia de la resolución, resulten necesarias mientras se mantenga la medida cautelar de suspensión del acto impugnado (art. 117.4 LPAC).

\section{En especial, el régimen de adopción de las medidas previas al inicio del procedimiento}

Ahora bien, la LPAC contempla relevantes novedades relativas a las medidas previas a la iniciación del procedimiento. Entre tales novedades debe destacarse, singularmente, que la adopción de estas medidas no queda ya limitada a los supuestos en los que así lo prevea una ley sectorial, pues la LPAC ha suprimido tal requisito, de manera que ha generalizado la posibilidad de adoptar medidas provisionales antes de la iniciación del procedimiento.

Tampoco debe desdeñarse que la nueva regulación haya añadido el carácter "inaplazable» de la urgencia que legitima la adopción de medidas provisionales antes de la iniciación del procedimiento administrativo.

Parece lógico que la adopción de medidas provisionales responda a razones de urgencia en todo caso, también tras el inicio del procedimiento, pues, de lo contrario, la protección de los intereses o derechos implicados podría esperar a la ejecución de la resolución que se dicte. Iniciado el procedimiento, con carácter general, serán razones de urgencia las que aconsejen adoptar medidas provisionales para evitar que, mientras se instruye y termina el procedimiento, se mantengan situaciones que puedan mermar o eliminar la eficacia real de la resolución final (18).

En consecuencia, cabe pensar que la referencia expresa a la urgencia inaplazable determinante de la adopción de las medidas provisionales previas a la incoación del procedimiento que ahora introduce el art. 56.2 LPAC ha de tener un significado especial. Por ello, será preciso razonar la

(17) Tal como deriva del art. 90.3 LPAC, en la resolución que ponga fin al procedimiento podrán adoptarse medidas provisionales distintas de las que, en su caso, se hayan adoptado durante el procedimiento.

(18) En este sentido se pronunciaba el art. 15.1 REPEPOS, al disponer: "Cuando así venga exigido por razones de urgencia inaplazable, el órgano competente para iniciar el procedimiento o el órgano instructor podrá adoptar las medidas provisionales que resulten necesarias". 
necesidad de adoptar inmediatamente estas medidas, por referencia a la posibilidad clara y evidente de riesgos o perjuicios inminentes, irreparables(19). A su vez, la citada exigencia puede servir de contrapeso a la posibilidad de adoptar estas medidas en cualquier procedimiento, sin necesidad de previsión expresa en una ley.

En otro orden de ideas, el art. 56.2 LPAC señala que las medidas provisionales previas a la iniciación del procedimiento podrán ser acordadas por "el órgano competente para iniciar o instruir el procedimiento", mientras que, con anterioridad, el art. 72.2 LRJPAC simplemente disponía su adopción por el "órgano competente». Esta previsión recuerda a otras disposiciones normativas que, una vez iniciado el procedimiento y por motivos de urgencia inaplazable, excepcionaban la regla general del órgano competente para resolver y permitían que las medidas provisionales necesarias fuesen acordadas por el órgano competente para iniciar o instruir el procedimiento (20).

En realidad, el avance del art. 56.2 LPAC en la concreción del órgano competentes es relativo, pues, en principio, la dicción del precepto mencionado permitiría entender que las medidas anteriores al inicio del procedimiento podrían ser acordadas indistintamente por el órgano competente para iniciar el procedimiento o por el órgano con competencia para instruirlo.

La determinación del concreto órgano competente para acordar estas medidas no presentaría ningún problema en los casos en que un mismo órgano tenga atribuida la competencia para iniciar e instruir el procedimiento. Sin embargo, la cuestión varía en los procedimientos en los que las fases de iniciación y resolución, por un lado, y la de instrucción deben encomendarse a órganos distintos, como ocurre en los procedimientos sancionadores (21).

Por otra parte, no será frecuente que el órgano competente para la instrucción pueda adoptar medidas provisionales antes de la iniciación del procedimiento, pues no es inusual que el instructor sea designado tras la iniciación del procedimiento en cuestión.

En definitiva, para mayor concreción sobre el órgano u órganos competentes para acordar medidas provisionales antes del inicio del procedi-

(19) Vid., al respecto, STS de 14 de noviembre de 2007, recurso núm. 77/2004. También la STS de 20 de marzo de 2012, recurso núm. 1501/2008, ha concretado que las situaciones de inaplazable urgencia que exigen la adopción inmediata e inaplazable de la medida provisional son situaciones de emergencia. En el ámbito doctrinal, también GOSÁLBEZ PEQUEÑO, Humberto, ha concluido que, más que urgencia parece que el legislador requiere un estado de "emergencia" para poder adoptar las medidas en cuestión. Vid., "El procedimiento administrativo común: iniciación y ordenación», en GOSÁLBEZ PEQUEÑO, Humberto (Dir.), La nueva Ley del Procedimiento Administrativo Común, Wolters Kluwer, Madrid, 2016, pág. 270.

(20) Nuevamente, es el caso del art. 15.1 REPEPOS, citado en páginas precedentes.

(21) Art. 63.1 LPAC. 
miento habrá que estar a lo que establezca la normativa reguladora de cada procedimiento.

\section{La audiencia previa al interesado}

En la redacción del art. 56 LPAC se ha omitido cualquier mención de la audiencia previa como requisito para la adopción de medidas provisionales, sin que existan elementos de juicio para apreciar si se trata de un propósito decidido o de un mero olvido del legislador. La audiencia previa al interesado no se menciona en el art. 56, a no ser que se entienda exigible por la remisión que este precepto efectúa a la LEC.

Conviene recordar que, durante la vigencia de la Ley 30/1992, la jurisprudencia ha venido admitiendo abiertamente que, a falta de mención expresa de este requisito en el art. 72, pueden acordarse las medidas provisionales sin previa audiencia a los interesados(22). Añadidamente, los Tribunales han argumentado que, dada la urgencia con que deben acordarse las medidas, si se espera y se concede plazo para la audiencia, mientras tanto podría consumarse la situación que se trata de evitar con la medida procedente(23). No obstante, ocasionalmente, la jurisprudencia ha exigido este trámite de audiencia en los procedimientos sancionadores (24), pese a no estar previsto en su normativa reguladora.

La audiencia a quien haya de soportar una medida provisional resulta muy conveniente, si no necesaria, para evitar que, tal como exige la Ley

(22) Entre otras, STSJ de Baleares de 24 de diciembre de 2002, recurso núm. 1060/2000.

(23) Vid., STS de 17 de julio de 2000, recurso núm. 2757/1993, y STSJ de Castilla y León de 12 de noviembre de 2004, recurso núm. 244/2003.

(24) Según la STS de 15 de julio de 2008, recurso núm. 5357/2004: «(...) al no ser automática la medida cautelar y comportar la alteración de una situación de hecho, el afectado por la misma debió ser previamente oído, dándole la oportunidad de aportar las pruebas tendentes a demostrar la improcedencia de la misma o los perjuicios que le pudiese causar.

La necesaria audiencia previa aparece directamente relacionada con el deber de motivar la medida, que sólo por razones de inaplazable urgencia cabría adoptar inaudita parte, pero siempre mediante explícita justificación, (...)».

La STS de 20 de marzo de 2012, recurso núm. 1501/2008, reitera lo dispuesto por la STS de 15 de julio de 2008, y añade lo siguiente: "Consiguientemente, la adopción de la medida provisional inaudita parte requiere una específica motivación que exteriorice no sólo la procedencia de la medida y su justificación desde la perspectiva de salvaguardia del interés general y la protección de los bienes jurídicos concernidos, sino también la necesidad de prescindir del trámite de audiencia por existir una situación de inaplazable urgencia, esto es de emergencia, que exige la adopción inmediata e inaplazable de la medida provisional, pues, si no existe esa situación de emergencia, lo procedente es oír a la parte afectada antes de acordar una medida provisional que al fin y al cabo repercutirá desfavorablemente sobre su esfera de intereses personales y patrimoniales. En una materia como la sancionadora, en la que tan importante resulta salvaguardar las garantías inherentes al derecho de defensa, la posibilidad de eludir este trámite de audiencia previa debe ser valorada y aplicada pues, de forma restrictiva y rigurosamente justificada». 
(art. 56.4 LPAC), su adopción vulnere los derechos de los interesados o pueda ocasionarles perjuicios de difícil o imposible reparación.

No existe razón para que el trámite de audiencia sea obviado sistemáticamente en la adopción de medidas provisionales en los procedimientos administrativos. La LPAC ha desaprovechado la oportunidad de incorporar la exigencia de audiencia previa al régimen de las medidas provisionales, bien con carácter previo a su adopción, como regla general, o con posterioridad a la misma si razones de urgencia inaplazable impiden o desaconsejan observar este trámite antes de acordar la medida correspondiente. Así se contempla en procedimientos administrativos regulados en normas sectoriales (25). Otro tanto ocurre en la regulación de las medidas cautelares que lleva a cabo la LJCA (26), y también es el caso de la LEC (27), norma a la que precisamente se remite el art. 56.3 LPAC.

\section{Principios rectores de la adopción de medidas provisionales}

Según la LPAC, una vez iniciado el procedimiento, las medidas provisionales se adoptarán de acuerdo con los principios de proporcionalidad, efectividad y menor onerosidad (art. 56.1).

Sin embargo, también de conformidad con la LPAC, antes de la iniciación del procedimiento administrativo, se podrán adoptar las medidas provisionales que resulten necesarias y proporcionadas (art. 56.2).

De entrada, estas referencias a los principios rectores de la adopción de las medidas provisionales o a las características que deben revestir las mismas suponen una novedad en la regulación de la LPAC, pues, con anterioridad, el art. 72 de la Ley 30/1992 no incluía ninguna de estas menciones (28). No obstante, en la jurisprudencia (29) podían encon-

(25) Así, por ejemplo, la Ley valenciana 10/2000, de 12 de diciembre, de Residuos, dispone en su art. 81.2) que «(...) no se adoptará ninguna medida provisional sin el trámite de audiencia previa a los interesados, salvo que concurran razones de urgencia que aconsejen su adopción inmediata, basadas en la producción de un daño grave para la salud humana o el medio ambiente, o que se trate del ejercicio de una actividad regulada en esta Ley sin la preceptiva autorización o con ella caducada o suspendida, en cuyos casos la medida impuesta deberá ser revisada, ratificada o dejada sin efecto tras la audiencia a los interesados".

(26) Arts. 131 y 135.1.a).

(27) Art. 733.

(28) Por lo que respecta a la exigencia de proporcionalidad, a juicio de COLOM PIAZUELO, Eloy, se encontraba ya establecida con carácter general en el art. 53.2 LRJPAC (hoy, art. 34.2 LPAC). Vid., "Artículo 72. Medidas provisionales", en SÁNCHEZ MORÓN, Miguel, y MAURANDI GUILLÉN, Nicolás, Comentarios a la Ley 30/1992, Lex Nova/Thomson Reuters, 2013, pág. 486.

(29) Una completa selección de jurisprudencia relativa a las medidas provisionales administrativas puede consultarse en MESEGUERYEBRA, Joaquín, Las medidas provisionales en vía administrativa, Bosch, Barcelona, 2000, pág. 59 y ss.; MARINA JALVO, Belén, Las medidas provisionales ..., op. cit., pág. 195 y ss. 
trarse algunas referencias generales a los principios mencionados (30), de las que no siempre podía extraerse con claridad el significado y alcance de los mismos.

Por el contrario, en el caso de las medidas provisionales de posible adopción en los procedimientos sancionadores, el art. 15.3 del REPEPOS sí disponía que deberían «(...) ajustarse a la intensidad, proporcionalidad y necesidades de los objetivos que se pretenda garantizar en cada supuesto concreto", y la jurisprudencia se ha ocupado de comprobar la concurrencia de estas exigencias (31).

Ahora bien, de una primera lectura e interpretación literal de los preceptos indicados de la LPAC podría extraerse que la adopción de medidas provisionales no se rige por las mismas reglas cuando tiene lugar antes de la iniciación del procedimiento que cuando coincide con el inicio del mismo o se da con posterioridad a dicho trámite. Ateniéndonos al tenor literal de los preceptos citados, parecería entonces que las medidas adoptadas ya iniciado el procedimiento no tienen que resultar necesarias y que tampoco las medidas adoptadas antes de la iniciación del procedimiento tendrían que reunir las exigencias de efectividad y menor onerosidad. Parece obvio que la adopción de una medida provisional ha de resultar necesaria en todo caso, en el sentido de imprescindible, con independencia del momento en que se adopte, pues, de lo contrario, la protección de los intereses o derechos implicados en cada caso podría esperar hasta el momento de dictarse la resolución final. El carácter necesario o inaplazable debe predicarse de las medidas acordadas una vez iniciado el procedimiento, y mucho más si se tiene en cuenta que ahora la LPAC (art. 96.1) contempla la posibilidad de tramitación simplificada del procedimiento en determinados supuestos. Tanto o más cabe decir de la necesidad de las medidas previas al inicio del procedimiento, considerando, además, que según dispone el art. 56.2 LPAC, no podrán ser objeto de recurso hasta el momento en que se inicie el procedimiento en cuestión (32), suponiendo que efectivamente llegue a iniciarse. La exigencia de necesidad de estas medidas debería ponerse

(30) Así, refiriéndose al art. 72 LRJPAC, la STS de 1 de diciembre de 2003, recurso núm. 914/1998, señalaba que "(...) la Administración ha de respetar en la adopción de tales medidas los principios de proporcionalidad, justificación y adecuación a su finalidad, debiendo ser decidida la tutela cautelar de la efectividad del eventual resultado del procedimiento administrativo en función de una mera valoración indiciaria de la importancia que presenten los concretos intereses en conflicto".

(31) Vid., entre otras, STS de 28 de febrero de 2012, recurso núm. 4396/2010.

(32) No obstante, las medidas en cuestión deberían ser recurribles igualmente en caso de que finalmente el procedimiento no se inicie.

En los mismos términos, véase, también GONZÁLEZ RíOS, Isabel, Reglas generales de ordenación e instrucción del procedimiento ..., op. cit., pág. 1543. 
en relación también con el carácter inaplazable de la urgencia que legitima su adopción.

A su vez, como es lógico, las medidas provisionales que hayan de acordarse antes de la iniciación del procedimiento deberían ser igualmente acordes con los principios de proporcionalidad, efectividad y menor onerosidad.

Avanzando entonces en la concreción de los principios que han de observarse en la adopción de medidas provisionales, pocas dudas presenta la exigencia de efectividad, pues es obvio que debe tratarse de medidas efectivas, es decir, idóneas para asegurar el objetivo pretendido en cada ocasión, bien sea la ejecución de la resolución final o bien la protección provisional de los intereses o derechos en juego.

En cuanto a la exigencia de optar por la medida que resulte menos onerosa para el sujeto que haya de padecerla (33), por regla general, para que pueda ser atendida será preciso que existan varias medidas que sirvan para atender de forma efectiva el fin perseguido(34). En realidad, dado que la LPAC permite adoptar cualquier medida necesaria para asegurar la efectividad de la resolución, no será fácil concluir de forma unívoca sobre si la medida en cuestión, elegida entre una pluralidad indeterminada de medidas provisionales, se ajusta a la exigencia de menor onerosidad.

Tampoco resulta exenta de dudas la determinación del alcance del principio de proporcionalidad, que también condiciona la adopción de medidas provisionales, y cuyo significado no aclara el art. 56 LPAC.

Este principio se menciona en otros preceptos de la propia LPAC $-\mathrm{y}$ también de la Ley 40/2015, de Régimen Jurídico de Sector Público (LRJSP) - relativos a diversas manifestaciones de la actividad administrativa con incidencia en los derechos e intereses legítimos de los particulares, y en ninguno de ellos se define, pese a lo cual, en cada ocasión parece tener connotaciones distintas (35).

(33) En palabras de GOSÁLBEZ PEQUEÑO, Humberto, la tipificación expresa del principio de menor onerosidad, "(...) no sólo condiciona la elección de una determinada medida provisional y no otra igualmente congruente y de intensidad proporcionada, sino que también condiciona la adopción misma de cualquier medida provisional, su propia existencia», El procedimiento administrativo común ..., op. cit., pág. 269.

(34) En los términos de la STS de 15 de enero de 2002, recurso núm. 155/1998, «(...) el principio de proporcionalidad opera con carácter ordinario en los casos en los que el ordenamiento jurídico admite la posibilidad de elegir uno entre vario medios utilizables y sólo con carácter excepcional, y en conexión con los principios de buena fe y equidad, en los supuestos en los que aun existiendo en principio un único medio éste resulta a todas luces inadecuado y excesivo en relación con las características del caso contemplado".

(35) Ya se alertó en la doctrina que a causa de «(...) la progresiva extensión de los principios de proporcionalidad y favor libertatis - que de principios específicos de la actividad de policía han pasado a ser considerados principios generales de cualquier actividad pública de incidencia negativa sobre 
Así, por lo que respecta a la regulación del procedimiento administrativo, se dispone que solo mediante ley podrán incluirse trámites adicionales o distintos a los contemplados por la LPAC, "cuando resulte eficaz, proporcionado y necesario para la consecución de los fines propios del procedimiento" (art. 1.2 LPAC).

En el caso de la ejecución forzosa de los actos administrativos el art. 100 LPAC dispone que se efectuará «(...) respetando siempre el principio de proporcionalidad" y, si fueran varios los medios de ejecución admisibles, "(...) se elegirá el menos restrictivo de la libertad individual».

En relación con el ejercicio de la potestad reglamentaria, sujeto a los principios de buena regulación, el art. 129 LPAC menciona, entre otros, el principio de proporcionalidad, en cuya virtud "(...) la iniciativa que se proponga deberá contener la regulación imprescindible para atender la necesidad a cubrir con la norma, tras constatar que no existen otras medidas menos restrictivas de derechos, o que impongan menos obligaciones a los destinatarios" (art. 129.3 LPAC).

En la LRJSP (art. 4.1), cuando se trata de establecer los principios rectores de la intervención de las Administraciones Públicas en el desarrollo de una actividad privada, se dispone que éstas "(...) deberán aplicar el principio de proporcionalidad y elegir la medida menos restrictiva, motivar su necesidad para la protección del interés público así como justificar su adecuación para lograr los fines que se persiguen, (...)».

Cuando opera como principio rector de la potestad sancionadora, el principio de proporcionalidad exige «(...) observar la debida idoneidad y necesidad de la sanción a imponer y su adecuación a la gravedad del hecho constitutivo de la infracción» (art. 29.3 LRJSP).

De los preceptos referidos puede extraerse que el principio de proporcionalidad comporta, por un lado, la exigencia de que las diversas manifestaciones de la actividad administrativa con incidencia en los derechos o intereses legítimos de los particulares $y$, por lo que ahora importa, las medidas provisionales, resulten necesarias para atender a los fines propios de la actividad administrativa en cuestión. Por otro lado, la medida dispuesta por la Administración habrá de resultar idónea, adecuada o eficaz para alcanzar el fin perseguido en cada caso(36). Por último, la exi-

\footnotetext{
los ciudadanos - se ha perdido su contenido preciso pasando a tener un significado vago y diverso según los casos; ahora se les puede invocar para cualquier cosa pero al precio de no decir casi nada y sin que se sepa si es algo distinto de la congruencia, de la adecuación, de la interdicción de la arbitrariedad, de la razonabilidad o simplemente de la justicia que, como la armonía, tuvo que ver siempre con las proporciones", REBOLLO PUIG, Manuel, Medidas provisionales en el procedimiento administrativo ...., op. cit., pág. 670.
}

(36) La jurisprudencia califica de desproporcionadas las medidas provisionales que resultan innecesarias o inadecuadas para preservar los intereses en juego. Vid., por ejemplo, SSTS de 27 de julio de 1999, recurso núm. 1419/1992, y de 29 de abril de 2002, recurso núm. 1779/1996. 
gencia de proporcionalidad implica que la actuación administrativa no solo no habrá de incurrir en exceso para salvaguardar el derecho o interés correspondiente(37), sino que, en ocasiones, incluso, como ocurre con las medidas provisionales, deberá ser la menos restrictiva de entre las posibles. Será excesiva en todo caso, y por ello desproporcionada, una medida provisional que ocasione al interesado perjuicios de imposible o difícil reparación o que suponga una vulneración innecesaria de derechos amparados por las leyes (38).

Las conclusiones expuestas coincidirían con la formulación doctrinal del principio de proporcionalidad(39), en cuya virtud éste exige, por un lado, que cuando una actuación resulte necesaria, se opte por la alternativa más idónea para alcanzar el resultado pretendido. Por otro lado, la exigencia de proporcionalidad comportaría la necesidad del debido equilibrio entre la concreta intervención, el fin perseguido y la afección del derecho o libertad que resulta de tal intervención.

Por lo demás, y pese a la falta de referencias expresas del art. 72 LRJPAC a estos principios rectores de la adopción de medidas provisionales, la jurisprudencia ha venido exigiendo su observancia e interpretando los mismos en términos similares a los aquí señalados (40).

Si se acude a la regulación de las medidas cautelares en la LEC, norma a la que remite el art. 56.3 LPAC, se observa que no menciona expresamente el principio de proporcionalidad. No obstante, al regular las características de las medidas cautelares, la LEC (art. 726.1) dispone que el tribunal podrá acordar como medida cautelar cualquier actuación que sea exclusivamente conducente a hacer posible la efectividad de la tutela ju-

(37) Así puede extraerse también de la STC de 26 de noviembre de 1984, que al enjuiciar la adopción de medidas provisionales en un procedimiento sancionador señala: «(...) la presunción de inocencia es compatible con la aplicación de medidas cautelares siempre que se adopten por resolución fundada en derecho que, cuando no es reglada, ha de basarse en un juicio de razonabilidad acerca de la finalidad perseguida y las circunstancias concurrentes, pues una medida desproporcionada e irrazonable no será propiamente cautelar, sino que tendría un carácter punitivo en cuanto al exceso".

(38) En este sentido, puede verse también, COLOM PIAZUELO, Eloy, Medidas provisionales ..., op. cit., pág. 487.

(39) Vid., LÓPEZ GONZÁLEZ, José Ignacio, El principio general de proporcionalidad en el Derecho Administrativo, Instituto García Oviedo, Sevilla, 1988, págs. 56 y siguientes.

Las exigencias de necesidad de la medida, idoneidad y proporcionalidad en sentido estricto integran el denominado "test alemán de proporcionalidad», según señala GONZÁLEZ BEILFUSS, Markus, "Últimas tendencias en la interpretación del principio de proporcionalidad por parte del Tribunal Constitucional», en CARRASCO DURÁN, Manuel (Coord.), Derecho Constitucional para el siglo XXI, Aranzadi, Pamplona, 2006.

(40) Según señala la STSJ de Cantabria de 24 de septiembre de 1998, recurso núm. 2487/1997, la motivación de la adopción de las medidas provisionales debe referirse a «(...) la necesidad de la adopción de las medidas mismas, su conexión con la garantía del procedimiento y la resolución final que recayera, su adecuación a tales fines, su elección preferente respecto de otras medidas menos restrictivas de la libertad (...)». 
dicial que pudiera otorgarse, y que no sea susceptible de ser sustituida por otra medida igualmente eficaz, pero menos gravosa o perjudicial para el demandado.

Refiriéndose específicamente al embargo preventivo, la LEC (art. 727.1) dispone que tal medida podrá acordarse siempre que resulte ser medida idónea y no sustituible por otra de igual o superior eficacia y menor onerosidad para el demandado.

A su vez, cuando la LEC contempla que el demandado pueda solicitar la caución sustitutoria de las medidas cautelares, señala que, para decidir sobre tal petición, el tribunal también tendrá en cuenta si la medida cautelar en cuestión «(...) habría de restringir o dificultar la actividad patrimonial o económica del demandado de modo grave y desproporcionado respecto del aseguramiento que aquella medida representaría para el solicitante» (art. 746.2).

En definitiva, importa resaltar que no debe obviarse la relevancia de las referencias a los principios de necesidad, proporcionalidad, efectividad y menor onerosidad incorporadas de forma expresa por el art. 56 LPAC, ni éstas deben entenderse como meras formalidades. Se trata de verdaderas exigencias cuya concurrencia deberá motivarse de forma explícita y detallada por la Administración, que condicionan la adopción de las medidas provisionales, y pueden ser útiles para combatir la arbitrariedad en la elección de la concreta medida, pero no eliminan la discrecionalidad administrativa(41), habida cuenta de que el mencionado principio de proporcionalidad no tiene un significado claro y preciso y, por tanto, resulta interpretable (42).

(41) Sin embargo, en ocasiones, la jurisprudencia sostiene lo contrario. Así, tal como señala la STS de 16 de febrero de 2009, recurso núm. 1887/2007, y reitera la STS de 20 de marzo de 2012, recurso núm. 1501/2008, «(...) al aplicar medidas provisionales la Administración no dispone de un margen de apreciación que le permita optar entre distintas opciones, todas igualmente justas y admisibles para el ordenamiento jurídico, sino que debe buscar la solución adecuada para el lance concreto, a la vista de la finalidad perseguida y de las circunstancias concurrentes. No actúa, pues, una potestad discrecional sino otra reglada, dirigiéndose hacia la única meta pertinente en atención a las singularidades del supuesto, orientándose con las pautas que le proporcionan los principios de proporcionalidad y equidad, a fin de evitar, tal y como recuerda el artículo 72, apartado 2, de la Ley 30/1992, causar perjuicios de difícil o imposible reparación a los interesados".

(42) No deben obviarse los riesgos derivados de la invocación del principio de proporcionalidad "(...) que todo lo matiza y cuestiona según el concreto caso de que se trate», tal como afirma BARNÉS VÁZQUEZ, Javier, "Introducción al principio de proporcionalidad en el Derecho comparado y comunitario", en RAP, núm. 135, 1994, pág. 52.

De ahí la importancia de los intentos dogmáticos de concretar y racionalizar el contenido del principio de proporcionalidad, dado el carácter tan indeterminado de este principio. Vid., GONZÁLEZ BEILFUSS, Markus, Últimas tendencias en la interpretación del principio de proporcionalidad ..., op. cit. 


\section{La necesaria motivación del acuerdo de adopción de medidas provisionales}

Si bien el art. 54.1.d) LRJPAC mencionaba ya la adopción de medidas provisionales entre los actos administrativos de obligada motivación, tal requisito aparece ahora contemplado por partida doble en el art. 56.2 LPAC y en el art. 35.1.d) de la misma Ley, de manera que no debe desdeñarse la relevancia de esta exigencia específica de motivación (43).

La motivación en cuestión habrá de referirse a la concurrencia de los requisitos exigidos por el art. 56 LPAC para la adopción de medidas provisionales. Por tanto, la motivación deberá expresar la existencia de elementos de juicio suficientes de los que deriva la necesidad de acordar una determinada medida provisional para evitar situaciones jurídicas que pudieran ser incompatibles con la efectividad -en sentido amplio - de la resolución que pueda recaer; la concurrencia de los principios rectores de la adopción de estas medidas (necesidad, idoneidad, menor gravosidad) (44), que implica la ponderación de los diversos intereses en juego; así como, en definitiva, la proporcionalidad de la medida elegida, que no podrá ocasionar perjuicios de imposible o difícil reparación a los interesados, ni violación de derechos amparados por las leyes (45).

Para que sea posible comprobar que, en función de las circunstancias del caso concreto (46), la medida reúne los requisitos del art. 56 LPAC, no bastará una sucinta referencia de hechos y fundamentos de

(43) En referencia concreta a las medidas provisionales acordadas en un procedimiento sancionador, cuya normativa exigía expresamente que se adoptasen mediante acuerdo motivado, la STS de 15 de julio de 2008, recurso núm. 5357/2004, recuerda que «El precepto contenido en los artículos 136 de la Ley 30/1992 y 15.1 del Reglamento aprobado por Real Decreto 1398/93, es categórico en cuanto exige una específica motivación que justifique la adopción de la medida de carácter provisional, de manera que no basta, para cumplir con el deber de motivar la medida cautelar, expresar los hechos constitutivos de la infracción, su calificación y las posibles sanciones, sino que es necesario explicar y exponer las razones por las que se acuerda la medida provisional (...)".

(44) Según señala la STSJ de Cantabria de 24 de septiembre de 1998, recurso núm. 2487/1997, la motivación de la adopción de las medidas provisionales debe referirse a «(...) la necesidad de la adopción de las medidas mismas, su conexión con la garantía del procedimiento y la resolución final que recayera, su adecuación a tales fines, su elección preferente respecto de otras medidas menos restrictivas de la libertad (...)").

(45) Sobre el contenido de la motivación de la adopción de medidas provisionales, en términos parecidos a los expresados en el texto, también puede verse GALLARDO CASTILLO, María Jesús, Los procedimientos administrativos en la Ley 39/2015 ..., op. cit., págs. 207-208.

(46) En los términos de la STS de 20 de marzo de 2001, rec. 8121/1996, se requiere una motivación suficiente, que exprese las circunstancias y razones que justifican la medida provisional adoptada, "(...) a efectos de realizar el juicio de razonabilidad sobre la finalidad y proporcionalidad". 
derecho, sino que deberá existir una motivación real, suficiente y no meramente formal (47).

Desde otra perspectiva, habida cuenta de lo expuesto, el deber de motivar está estrechamente relacionado con la conveniente audiencia previa al interesado, de ahí la necesidad de una motivación adicional y específica en los casos en que la medida sea adoptada inaudita parte(48).

\section{Las medidas provisionales de posible adopción en los procedimientos administrativos}

\section{La remisión a la Ley $1 / 2000$, de 7 de enero, de Enjuiciamiento Civil}

Son varias las consideraciones oportunas en relación con la remisión que en este punto la LPAC hace a la LEC. En primer lugar, resulta cuestionable la remisión a la ley procesal civil, como si la normativa reguladora del procedimiento administrativo y, en su caso, la regulación de las medidas cautelares que lleva a cabo la Ley 29/1998, de 13 de julio, Reguladora de la Jurisdicción Contencioso-Administrativa (LJCA) (49) no constituyesen referencias suficientemente próximas y completas para integrar el régimen de las medidas provisionales administrativas.

En segundo lugar, existe una distancia obvia entre un proceso judicial y un procedimiento administrativo y también entre las medidas cautelares adoptadas en cada uno de estos ámbitos. Por obvio que sea, no está de más resaltar que, en el primer caso las medidas se adoptan por un Tribunal para garantía de la tutela judicial efectiva, y en el segundo caso se acuerdan por un órgano administrativo para asegurar la efectividad de la resolución que pueda recaer en el procedimiento.

(47) La STS de 12 de marzo de 2012, recurso núm. 1070/2009, señala que «(...) la motivación de la medida, más que un requisito formal, es el elemento estructural y básico de la resolución e ineludible para valorar su justificación, pues, de otro modo, no sería posible fiscalizar su respeto al principio de proporcionalidad ni la concurrencia de motivos que la justifiquen».

(48) Así, la STS de 20 de marzo de 2012, recurso núm. 1501/2008, señala que «(...) la adopción de la medida provisional inaudita parte requiere una específica motivación que exteriorice no sólo la procedencia de la medida y su justificación desde la perspectiva de salvaguardia del interés general y la protección de los bienes jurídicos concernidos, sino también la necesidad de prescindir del trámite de audiencia por existir una situación de inaplazable urgencia, esto es de emergencia, que exige la adopción inmediata e inaplazable de la medida provisional, pues, si no existe esa situación de emergencia, lo procedente es oír a la parte afectada antes de acordar una medida provisional que al fin y al cabo repercutirá desfavorablemente sobre su esfera de intereses personales y patrimoniales".

(49) Con frecuencia la jurisprudencia ha puesto en relación la regulación de las medidas provisionales de la LRJPAC con los preceptos que regulan la justicia cautelar en la LJCA. Vid., entre otras, STS de 1 de octubre de 2003, recurso núm. 914/1998. 
En todo caso, existen diferencias considerables en aspectos esenciales de la regulación que de las medidas en cuestión hacen la LPAC y la LEC. La LEC dedica a la cuestión un Título completo (concretamente, el Título VI, "De las medidas cautelares», que comprende los arts. 721 a 747). Cabría entender que, en su caso, las disposiciones delTítulo mencionado serían de aplicación, con la necesaria adaptación, a la adopción de medidas provisionales administrativas. Las consecuencias de esta interpretación no son desdeñables, teniendo en cuenta que la LPAC permite acordar cualquier medida necesaria para asegurar la efectividad de la resolución, y que sus disposiciones no son demasiado prolijas en lo relativo a las garantías que han de rodear la adopción de tales medidas. La posición del sujeto pasivo de las medidas provisionales mejoraría y la eficacia de las mismas no se resentiría en todo caso si se observasen en el procedimiento administrativo disposiciones de la LEC tales como la regla general de audiencia previa al demandado, la exigencia - también como regla general- de caución al solicitante de la medida cautelar, la posibilidad de que el demandado pueda solicitar la sustitución de la medida cautelar por la caución suficiente, para evitar así que la medida cautelar pueda restringir o dificultar su actividad patrimonial o económica "(...) de modo grave y desproporcionado respecto del aseguramiento que aquella medida representaría para el solicitante» (art. 746.2 LEC).

Por otra parte, si como parece, el art. 56.3 LPAC se remite, en realidad, al elenco de las medidas contempladas por la LEC, también así carece de justificación que la ley reguladora del procedimiento administrativo se remita a una ley procesal. Como concluye el Dictamen del Consejo de Estado 275/2015, de 29 de abril, la LPAC no puede renunciar a regular esta materia con sustantividad propia, de modo que, en todo caso, la remisión a la LEC resulta innecesaria.

\section{Medidas provisionales de posible adopción}

El art. 56.3 LPAC contempla la posible adopción de las siguientes medidas:»a) Suspensión temporal de actividades; b) Prestación de fianzas; c) Retirada o intervención de bienes productivos o suspensión temporal de servicios por razones de sanidad, higiene o seguridad, el cierre temporal del establecimiento por estas $u$ otras causas previstas en la normativa reguladora aplicable; d) Embargo preventivo de bienes, rentas y cosas fungibles computables en metálico por aplicación de precios ciertos; e) El depósito, retención o inmovilización de cosa mueble; f) La intervención y depósito de ingresos obtenidos mediante una actividad que se considere ilícita y cuya prohibición o cesación se pretenda; g) Consignación o constitución de depósito de las cantidades que se reclamen; h) La 
retención de ingresos a cuenta que deban abonar las Administraciones Públicas; i) Aquellas medidas que, para la protección de los derechos de los interesados prevean expresamente las leyes, o que se estimen necesarias para asegurar la efectividad de la resolución".

Pues bien, lo cierto es que el citado art. 56.3 LPAC se limita a enumerar una serie de medidas provisionales de posible adopción por los órganos administrativos competentes, que no se corresponden precisamente con "los términos previstos" en la LEC. La enunciación de medidas provisionales de posible adopción que lleva a cabo el art. 56.3 LPAC permite comprobar que ni son todas las que están ni están todas las que se mencionan en el art. 727 LEC, que establece las «medidas cautelares específicas".

La LPAC no ha extrapolado a su texto de forma mimética todas las medidas específicas enunciadas en el art. 727 LEC, sino que ha incorporado algunas de esas medidas que, a su vez, aparecen desprovistas de los matices que las rodean en el art. 727 LEC y, por tanto, descontextualizadas. En particular, a diferencia de lo que ocurre en el art. 727 LEC, el art. 56.3 LPAC no se ha hecho eco de las indicaciones sobre los supuestos en que procede la adopción de las medidas enunciadas (50). En todo caso, si se tiene en cuenta que la eficacia de la resolución final o de unos mismos intereses o derechos presentes en el procedimiento podrían ser asegurados mediante diversas medidas mencionadas en la LPAC, en última instancia, la elección de la medida procedente en el caso concreto debería venir determinada por los principios establecidos en los apartados 2) y 3) del citado art. 56 LPAC.

En principio, la redacción empleada por la LPAC podría hacer pensar que dicha norma se propone enumerar de forma limitativa las medidas de posible adopción. Sin embargo, la LPAC - igual que la LEC - hace una enumeración ejemplificativa de medidas provisionales de posible adopción que no constituye un numerus clausus, pues concluye señalando, aquí sí en términos muy similares a los utilizados por la LEC, que podrán adoptarse todas aquellas medidas que, para la protección de los derechos de los interesados, prevean expresamente las leyes, o que se estimen necesarias para asegurar la efectividad de la resolución (art. 56.3.i LPAC). Así pues, más allá de las medidas orientadas a la protección de los dere-

(50) En el art. 727 LEC, «junto a cada medida concreta, por lo demás, el legislador establece en ocasiones presupuestos específicos de adopción, singularmente en lo relativo a la situación jurídica cautelable o tipo de pretensión para cuya efectividad se autoriza la adopción de la medida", ORMAZÁBAL SÁNCHEZ, Guillermo, en CORDÓN MORENO, F., ARMENTA DEU, T., MUERZA ESPARZA, J.J., TAPIA FERNÁNDEZ, I. (Coords.), Comentarios a la Ley de Enjuiciamiento Civil, Aranzadi, 2001, Vol. II, pág. 685. En parecidos términos, DÍEZ-PICAZO GIMÉNEZ, Ignacio, en DE LA OLIVA SANTOS, A., DIEZ-PICAZO GIMÉNEZ, I., VEGAS TORRES, I., BANACLOCHE PALAO, J., Comentarios a la Ley de Enjuiciamiento Civil, Civitas, 2001, pág. 1223. 
chos de los interesados, la redacción de este precepto de la LPAC no permite extraer que solo quepa la adopción de medidas provisionales expresamente previstas en ésta u otras leyes, como tampoco cabe derivar esa conclusión del art. 727 LEC(51), que ha inspirado el enunciado del referido art. 56.3 LPAC (52).

Visto que el art. 56 LPAC permite la adopción de todas las medidas precisas para la protección de los derechos de los interesados, si están expresamente previstas en una ley, o de cualquier otra que se considere necesaria para garantizar la efectividad de la resolución, es obvio que, entre ellas, se encuentran, como mínimo, todas las previstas por la legislación administrativa de carácter sectorial.

Por otra parte, entre el catálogo de concretas medidas enunciadas en el art. 56.3 LPAC - algunas de ellas son habituales en los listados de la legislación sectorial-, además de las que tienen por objeto la suspensión de las actividades o servicios contrarios a los intereses que deban ser atendidos en cada concreto procedimiento administrativo, predominan las orientadas a asegurar las obligaciones de contenido económico que pueda establecer la resolución que ponga fin al procedimiento. Si bien, sobre este particular, conviene tener en cuenta que, de conformidad con la Disposición adicional primera de la LPAC, y las especialidades por razón de la materia a las que ésta alude, una parte muy significativa de los procedimientos y actuaciones en los que se sustancian obligaciones de contenido económico se rigen por su normativa específica, de modo que en ellos la LPAC solo tendría aplicación supletoria. El art. 56.2 LPAC ha establecido un listado ejemplificativo de una serie de medidas provisionales de tipo conservativo idóneas para algunos procedimientos, pero que, por el contrario, podrían resultar insuficientes, por inadecuadas, para asegurar la efectividad de la resolución final en otros tipos de procedimientos administrativos.

En definitiva, al margen de la remisión a la LEC y de la enunciación de medidas provisionales, el art. 56.3 LPAC permite la adopción de cualquier medida provisional necesaria para asegurar la efectividad de la resolución, de la misma manera que el art. 72 LRJPAC permitía acordar

(51) Así lo estima la doctrina civilista, afirmando, en relación con el art. 727 LEC, que «(...) la ley permite la adopción de cualesquiera medidas que se ajusten a lo previsto en el art. 726, siendo la del artículo 727 una enumeración a título meramente ejemplificativo", ORMAZÁBAL SÁNCHEZ, Guillermo, en Comentarios a la Ley de Enjuiciamiento Civil , op. cit., pág. 693. También, DíEZ-PICAZO GIMÉNEZ, Ignacio, en Comentarios a la Ley de Enjuiciamiento Civil ..., op. cit., pág. 1218.

(52) Sin embargo, a juicio de NÚÑEZ SÁNCHEZ, Fernando, el art. 56.3.i) establece de forma rotunda la exigencia de la necesaria reserva legal para la adopción de medidas provisionales en el procedimiento administrativo. Vid., "Artículo 56. Medidas provisionales», en RECUERDA GIRELA, Miguel Ángel, Régimen Jurídico del Sector Público y Procedimiento Administrativo Común de las Administraciones Públicas, Aranzadi, Pamplona, 2016, pág. 471. 
cualesquiera medidas provisionales oportunas para asegurar la eficacia de la resolución. Así derivaba de su tenor literal y así lo ha interpretado la jurisprudencia, señalando que el citado art. 72 LRJPAC no establece al respecto otra regla que la de que sean medidas oportunas para asegurar la eficacia de las resoluciones, sin más límite que el del perjuicio irreparable o el de indefensión en los supuestos de tutela judicial efectiva (53).

\section{Valoración final}

En el régimen establecido por la LPAC se aprecian cambios de diverso significado en la regulación de las medidas provisionales. La nueva regulación otorga a la Administración más facilidades en la adopción de medidas provisionales, como deriva de la supresión de la exigencia de previsión legal expresa de la posibilidad de acordar tales medidas antes de la iniciación del procedimiento. Otros de estos cambios derivan de la nueva concepción del procedimiento administrativo común que incluye al procedimiento sancionador sujeto, por lo que ahora importa, a las reglas generales de adopción de medidas provisionales, de modo que podrá adoptarse en el mismo cualquier medida sin necesidad de que una norma distinta del art. 56 así lo prevea.

Por el contrario, hay otras disposiciones en el art. 56 LPAC que contribuyen a acotar las facultades de la Administración para la adopción de las medidas provisionales, que pueden reducir la discrecionalidad y pueden ser una garantía de acierto de la decisión administrativa. Es el caso, por ejemplo, de la necesidad de acordar las medidas correspondientes con sujeción a los principios de proporcionalidad, efectividad y menor onerosidad -si bien la ley no concreta el significado y alcance de estas exigencias-, así como de la necesidad de motivar la adopción de la medida en cuestión por referencia a los principios mencionados. Curiosamente, se trata de requisitos que ya contemplaba la normativa y la jurisprudencia, especialmente en relación con la adopción de medidas provisionales en los procedimientos sancionadores donde, tal como ya se ha dicho, la LPAC ha eliminado otras garantías adicionales que antes condicionaban la adopción de las medidas que nos ocupan.

A la hora de mencionar las medidas provisionales de posible adopción, el art. 56 LPAC ha efectuado una remisión innecesaria, inadecuada y parcial a la LEC que, si bien tiene cierta utilidad ejemplificativa, permite adoptar cualquier medida sin necesidad de que esté prevista en una ley.

(53) Vid., STSJ de Cataluña de 21 de enero de 1997, recurso núm. 1889/1994. 
Por otra parte, la LPAC ha omitido pronunciarse sobre diversas cuestiones relevantes del régimen de las medidas provisionales, entre las que cabe destacar la relativa a la conveniencia de oír previamente al sujeto pasivo de la medida.

A tenor de todo lo expuesto, en una valoración de conjunto, puede decirse que el art. 56 LPAC ha aumentado las facultades administrativas para la adopción de medidas provisionales, ya de por si amplias al amparo del art. 72 LPAC. Y ello sin perjuicio de los nuevos principios y exigencias incorporados por la LPAC para la adopción de medidas provisionales, cuyo significado y alcance no es demasiado concreto.

Trabajo recibido el 26 de mayo de 2017

Aceptado por el Consejo de Redacción el 20 de octubre de 2017 
LABURPENA: Administrazio Publikoen Administrazio Prozedura Erkidearen urriaren 1eko 39/2015 Legearen 56. artikuluak berrikuntza batzuk sartu ditu behinbehineko neurrien erregulazioan. Labur-labur esan dezakegu, batetik, 39/2015 Legeak murrizketa arautzaile batzuk sartu dituela behin-behineko neurriak hartzeko eremuan. Orain, prozedura oro har hasi aurretik har daitezke neurri horiek. Era berean, Administrazio Publikoen Administrazio Prozedura Erkidearen Legeak jasotzen duen administrazio-prozedura erkidearen ikuskera berriaren ondorioz, kasu bakoitzean behar diren behin-behineko neurriak hartu ahalko dira prozedura zehatzaileetan, araudi erregulatzailean aurreikuspen espezifikorik egon beharrik gabe.

Beste alde batetik, eskakizun gehigarri batzuk ezartzen ditu erregulazio berriak, kontuan hartu behar direnak administrazio-prozedura hori hasi aurretiko edo hasi ondorengo behin-behineko neurriak hartzean. Horrela, administrazioak neurri horiek hartzean duen irizpidezkotasuna murrizten lagunduko da.

Beste leku batetik begiratuta, nabarmendu egin behar da legegileak sartu dituen aldaketek hainbat inspirazio-iturriri erantzuten dietela, edo hori ematen duela; izan ere, Administrazio Publikoen Administrazio Prozedura Erkidearen Legeak Prozedura Zibilaren Legea hartu nahi izan du erreferentziatzat har daitezkeen behinbehineko neurriak zeintzuk diren adieraztean, baina, neurri horiek hartzeko modua arautzen duten printzipioei dagokienean, legegileak aurreko araudian prozedura zehatzaileetako behin-behineko neurriak hartzeko araubidea ezaugarritzen zuten zenbait berezitasuni begiratu diela dirudi.

GAKO HITZAK: Behin-behineko neurriak. Administrazio-prozedura. Ebazpenaren eraginkortasuna. Proportzionaltasuna. Motibazioa.

RESUMEN: El art. 56 de la Ley 39/2015, de 1 de octubre, de Procedimiento Administrativo Común de las Administraciones Públicas (LPAC) ha introducido algunas novedades en la regulación de las medidas provisionales. De forma resumida puede decirse que, por una parte, la Ley 39/2015 ha eliminado algunas restricciones normativas relativas a la adopción de las medidas provisionales, de manera que ahora éstas pueden ser acordadas antes del inicio del procedimiento con carácter general. A su vez, a consecuencia de la nueva concepción del procedimiento administrativo común que recoge la LPAC, en los procedimientos sancionadores podrán adoptarse las medidas provisionales precisas en cada caso, sin necesidad de previsión específica en la normativa reguladora.

Por otra parte, la nueva regulación establece una serie de exigencias adicionales que deben observarse al acordar las medidas provisionales previas o posteriores a la iniciación del procedimiento administrativo de referencia, contribuyendo así a reducir la discrecionalidad administrativa en su adopción.

Desde otra perspectiva, cabe destacar que los cambios introducidos por el legislador parecen responder a distintas fuentes de inspiración pues, mientras que en lo relativo a la enunciación de las medidas provisionales de posible adopción la LPAC ha pretendido tomar como referencia la Ley de Enjuiciamiento Civil, en lo que respecta a los principios que ordenan la adopción de las medidas señaladas el legislador parece haber tenido en cuenta, principalmente, algunas singularidades que, en la normativa precedente, caracterizaban al régimen de adopción de las medidas provisionales en los procedimientos sancionadores. 
PALABRAS CLAVE: Medidas provisionales. Procedimiento administrativo. Efectividad de la resolución. Proporcionalidad. Motivación.

ABSTRACT: Article 56 of Act 39/2015 of October 1st, on the Common Administrative Procedure by the Public Administrations provided some novelties in the regulation of interim measures. In brief we can consider that on the one hand Act 39/2015 has lifted some normative restrictions regarding the adoption of interim measures so that they now can be agreed in general before the beginning of the procedure. At the same time, as a consequence of the new common administrative procedure conception established by the LPAC, in penalty procedures interim measures specific to each case might be adopted without the need to be specifically stated by the governing regulation.

On the other hand, the new regulation has established a number of additional requirements to be observed when agreeing previous or subsequent interim measures to the beginning of the administrative procedure of reference, contributing to reduce administrative discretion at the time of their adoption.

From another angle, it should be noted that changes introduced by the legislator seem to respond to several sources of inspiration since whilst the establishment of interim measures to be adopted the LPAC intended to take as reference the Civil procedure law, concerning the principles that govern the adoption of the aforementioned measures, the legislator seem to have taken into account mainly some particular features that in the previous legislation characterized the system of adoption of interim measures in penalty procedures.

KEYWORDS: Interim measures. Administrative procedure. Effectiveness of the resolution. Proportionality. Motivation. 